\title{
Recrystallization of Enantiomers from Conglomerates
}

\author{
Valérie Dupray \\ Université de Rouen
}

France

\section{Introduction}

An object is considered as "chiral" if it is not superimposable on its mirror image. Due to the presence of asymmetric carbon atoms, numerous molecules are chiral but other stereogenic centers provide the asymmetric character of molecular compound (e.g. sulfoxides). Metalorganic complexes can also be asymmetric even if the ligands do not have any stereogenic center. The equimolar mixture of two enantiomers is the racemic mixture. Except for their rotatory powers which are equal in value but of opposite signs, enantiomers present identical chemical and physical properties in achiral environment. Conversely, their behaviors in chiral environment such as biological systems are often different. In particular, for chiral drugs, the pharmacological and the toxicological effects can be drastically dissimilar.

(a)
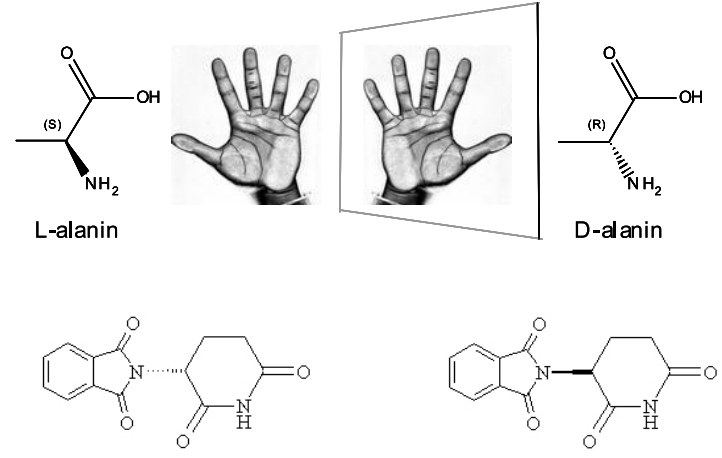

(b)

$$
\text { R-Thalidomide }
$$

S-Thalidomide

Fig. 1. Enantiomers of (a) Alanin and (b) Thalidomide

A well-known example is the case of thalidomide. Thalidomide was a drug prescribed for nausea during pregnancy in the later 1950s and was marketed as the racemic mixture. The R-enantiomer showed the desired curing effect while the S-enantiomer caused serious teratogenic effects (Kocher-Becker et al, 1982). The health scandal that follows led to the removal of the drug in 1961. Since, the pharmaceutical regulatory authorities have increased 
the pressure for chiral drugs to be administered in an enantiomerically pure form. Thus, chiral drug industry has been in constant development and has become the most growing segment of the drug market. It represents now more than one third of the drug sales worldwide (Stinson, 2000). At the same time, chemical producers have developed new enantiomeric intermediates for industry and especially enantioselective technologies. Asymmetric synthesis (a chemical reaction of an enantiomeric agent or catalyst with a substrate to produce a single enantiomer of the desired molecule) remains the first mode of production of pure enantiomers. However, the reaction product can appear to be a racemic mixture due to synthesis conditions or in rare occasions to racemization. Commonly, it is also cheaper, easier or cleaner to synthesize directly the racemic mixture. In those cases, a chiral resolution (separation) has to be performed to recover the pure enantiomer.

A direct enantiomeric separation can be carried out via chiral chromatography. To this purpose, the inner surface of a chromatographic column is bonded or coated with a chiral selector or alternatively the chiral selector can be incorporated directly to the stationary phase. As a result, the two enantiomers have different retention times which allow the resolution (Subramanian, 2006). However, this process which leads to high purity products, the productivity (which can be poor due to a high separation time and/or a small rate of injection of the product in the column) is not always compatible with industrial standards. Another solution consists of using crystallization.

The most popular crystallization method certainly remains the Pasteurian resolution (Pasteur, 1853) for which a chiral resolving agent is used to obtain the crystallization of diastereoisomers. Typically, the resolving agent (an enantiomerically pure acid (resp. base)) is added to the racemic base (resp. acid) to form diastereoisomeric salts. Contrary to the enantiomers, diastereoisomers do not exhibit the same symmetry (Coquerel, 2000) and as a consequence do not present the same chemical and physical properties (in particular solubility). Dissolution-recrystallization in an appropriate solvent or mix of solvents permits to obtain a single solid crystalline phase (the pure salt). Then, the pure enantiomer can be recovered by salting out to remove the resolving agent.

In order to improve the yield and to reduce the quantity of resolving agents, several variations have been proposed. Let us just mention the Marckwald's method (Marckwald, 1896), the Pope and Peachey's method (Pope \& Peachey, 1899) and more recently the Dutch resolution (Vries et al, 1998), (Kaptein et al, 2000). Note also that the accurate determination of the phase diagrams under the conditions of the experimental process allows an optimization of the resolution (Marchand et al, 2004). Even imperfect (a yield close to 100\% is rarely obtained), this method most often fits industrial and laboratories requirements.

Besides the Pasteurian method, the resolution can be performed by "preferential crystallization" (PC) also called "crystallization by entrainment". PC is a stereoselective process in which, alternatively, for a given period of time, only one enantiomer crystallizes although both enantiomers are supersaturated in the mother liquor. In 1866, Gernez (Gernez, 1866) was the first to observe that a saturated solution of one enantiomer, seeded by the same enantiomer, allows the formation of enantiomerically pure crystals. Conversely, he noted that if the seeding was done with the other enantiomer, no crystallization was observed. The entrainment phenomenon itself was described by Jungfleish (Jungfleish, 1882) who underlines the predominant influence of supersaturation. 
In the 1990s, the phenomena involved in the preferential crystallization have been explained in details in literature using phase diagrams. For a complete description please refer to Jacques and his co-workers book "Enantiomers, Racemates, and Resolution"(Jacques et al, 1994).

Several improvements of this cyclic process have been proposed such as the auto-seeded variant AS3PC developed by Professor Gerard Coquerel and co-workers at the French University of Rouen (Ndzié et al, 1997; Coquerel, 2007). AS3PC by its robustness, its low cost and reproducibility offers real possibilities for industrial applications of preferential crystallization. As a proof, the AS3PC process has been the subject of several patents for the University of Rouen (Coquerel et al, 1994; Coquerel et al, 1995; Helmreich et al, 2010)

The main advantage of PC and its derivatives is certainly that they do not require any resolving agent. However they suffer from a serious limitation: the compound to be resolved or accessible derivatives such as salts solvated or not, must crystallize as a conglomerate (ie. an equimolar mechanical mixture of crystals, each one containing only a single enantiomer). The requirement of a conglomerate is an important restriction to the application of preferential crystallization due to the low occurrence of conglomerates among the molecular crystallized compounds (5-10\% of the racemic species only)(Jacques et al, 1994).

Because the detection of a conglomerate is a key step of the resolution process, we chose to focus this contribution on this subject. The first part constitutes a necessary reminder about crystal packing of chiral molecules and includes the definition of the different types of structures that can be encountered crystallizing racemic mixtures. The second part is dedicated to the enantiopurification by crystallization. The benefits of working with conglomerates are underlined. The next part describes the detection of conglomerates itself. Classical methods are first recalled and then the prescreening of a conglomerate via a high throughput technique involving nonlinear optics is presented. In the last part, we propose a sequential diagram to optimize the detection of conglomerates.

\section{Crystal structure and packing of chiral molecules}

Speaking about crystallization and recrystallization implies to take into account the way the molecules are packed inside the crystal. It is all the more important as the chiral nature of a molecule imposes some limitations.

\subsection{Types of packing of chiral molecules}

Three most common types of packing are usually observed when crystallizing a racemic mixture (Coquerel, 2000):

- The racemic compound is the most common (90-95\% of racemic species). In the vast majority of the cases it is a $<1-1>$ stoichiometric compound.

- The conglomerate is a mechanical mixture of single crystals containing homochiral molecules only. As mentioned previously, conglomerates represent only 5 to $10 \%$ of the racemic species (Jacques et al, 1994).

- The racemic solid solution has a low occurrence. It is a solid solution containing an equal number of molecules of each enantiomer but contrary to the racemic compound, the arrangement is a random distribution (see fig.2) 


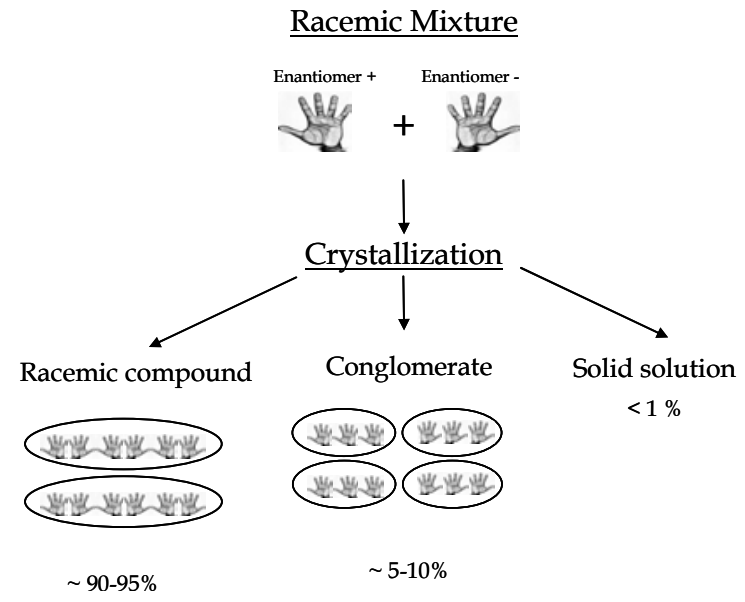

Fig. 2. Types of packing of chiral molecules

\subsection{Chirality of crystalline structures}

The nature of the crystalline structure formed by the chiral molecules is of major importance when considering the recrystallization processes. At this stage, it is imperative to distinguish between the chirality of the molecule itself and the chirality of the crystalline structure. Indeed, crystalline structures formed from enantiomers (chiral molecules) present in racemic mixture are not necessarily chiral. Let us just first recall that chiral crystals belong to space groups that contain only symmetry operation of the first kind (rotation, translation). It excludes the symmetry operations of the second kind (rotoinversion) which are allowed in non-centrosymmetric structures.

Crystalline structures can then be classified into three categories (Flack, 2003; Galland et al, 2009):

- Centrosymmetric (achiral) structures (type CA) which corresponds to point groups $\overline{1}$, $2 / \mathrm{m}, \mathrm{mmm}, 4 / \mathrm{m}, 4 / \mathrm{mmm}, \overline{3}, \overline{3} \mathrm{~m}, 6 / \mathrm{m}, 6 / \mathrm{mmm}, \mathrm{m} 3$ and $\mathrm{m} 3 \mathrm{~m}$.

- Non centrosymmetric achiral structures (type NA) for point groups $\mathrm{m}, \mathrm{mm} 2, \overline{4}, 4 \mathrm{~mm}$, $\overline{4} 2 \mathrm{~m}, 3 \mathrm{~m}, \overline{6}, 6 \mathrm{~mm}, \overline{6} \mathrm{~m} 2$ and $\overline{4} 3 \mathrm{~m}$.

- Non centrosymmetric chiral structures (type NC) associated with point groups 1, 2, 222, $4,422,3,32,6,622,23$ and 432.

Racemic compounds can theoretically be part of any space groups (CA, NA or NC) but $95 \%$ of the known racemic compounds crystallize in centrosymmetric space groups (CA). The predominant space groups are: $\mathrm{P} 2_{1} / \mathrm{c}, \mathrm{C} 2 / \mathrm{c}$, Pbca and $\mathrm{P} \overline{1}(95 \%)$ of the centrosymmetric racemic compounds)(Dalhus et al, 2000). Non centrosymmetric racemic compounds (NA) like DL-Allyglycine (Dalhus et al, 2000) represent a proportion of 4.5-5\%, mainly placed in space groups Pna21, Pca21, Cc and Pc. Rare cases of racemic compounds crystallizing in chiral space groups (mainly $\mathrm{P} 2{ }_{1} 2_{1} 2_{1}$ and $\mathrm{P} 2{ }_{1}$ ) have been reported (ortho-thyrosine, $\alpha-$ methylsuccinic acid or camphoroxime (Jacques et al, 1994; Brock et al, 1991; Kostaniovsky, 2008). Their occurrence is estimated to be only $0.02 \%$ (Flack et al, 2003). 
Regarding the conglomerate, the chiral nature of the molecules imposes restriction in the construction of the crystalline structure so it is impossible to form achiral crystal structures by crystallization of enantiomerically pure chiral molecules (Jacques et al, 1994), (Flack et al, 2003). Consequently, conglomerates crystallize only in one of the 65 chiral space groups (spaces groups $\mathrm{P} 2{ }_{1} 2_{1} 2_{1}, \mathrm{P}_{2}, \mathrm{C}_{2}$ and $\mathrm{P}_{1}$ represent $95 \%$ of the known conglomerates (Belsky et, 1977).

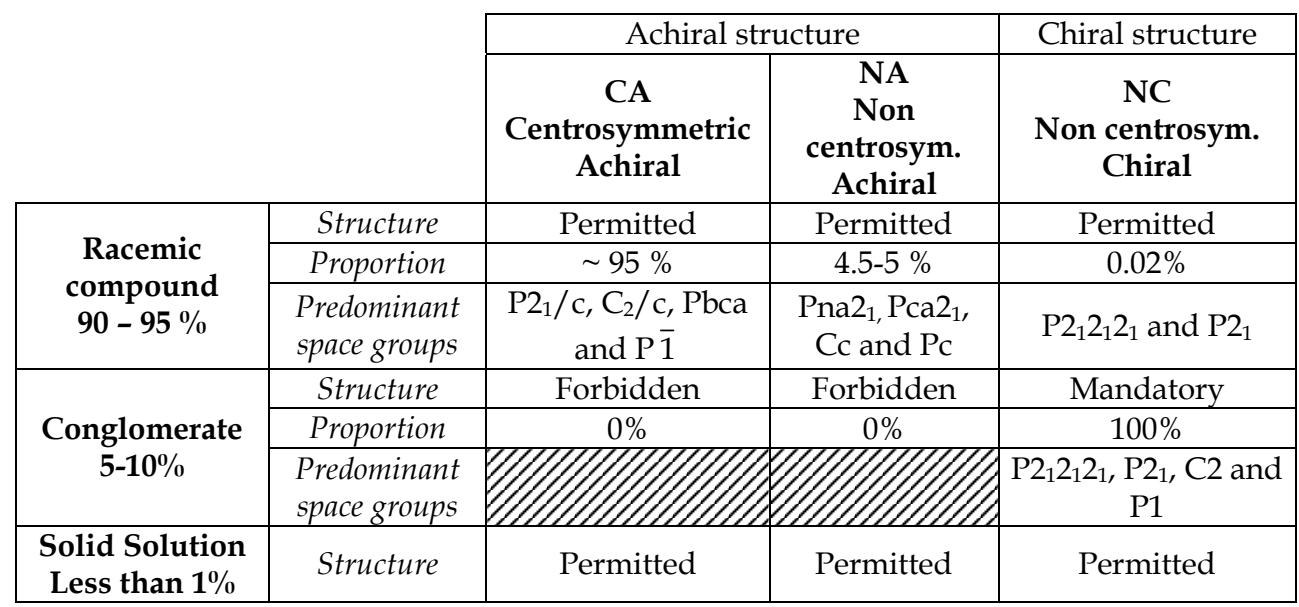

Table 1. Formation of crystalline structures from racemic mixtures

Concerning the solid solution, the three crystal types are permitted but no data seems available about the predominant space groups in the case of racemic solid solution. These various possibilities for the crystallization of racemic mixtures are summarized in Table 1.

\section{Recrystallization of enantiomers}

Enantiopurification by crystallization is presented here for two cases:

- a racemic compound-forming system using the classical selective crystallization processes

- a conglomerate for which a crystallization by entrainment is possible

The two recrystallization procedures require a good knowledge of the behavior of the two enantiomers regarding melting (binary phase diagrams) and solubility in a given solvent (Ternary phase diagrams). For a detail description of the various phase diagrams encountered for these systems of enantiomers, please refer to (Jacques et al, 1994), (Lorenz et al, 2006) and (Coquerel, 2000).

\subsection{Enantiopurification from racemic compound-forming system}

On figure 3 is depicted the usual ternary phase diagram observed for a racemic compoundforming system ( $S$ and $R$ enantiomers, racemic compound RS and solvent $V_{1}$ ) at a given temperature $T_{1}$. Six regions are delimited by the solubility curves (see legend of figure 3 ) and can contain from 1 to 3 phases. The size of theses different regions varies of course with temperature. 
Assuming that the mixture of enantiomers to purify (represented by point $\mathrm{M}$ ) has an enantiomeric excess exceeding that of the invariant liquid $\mathrm{I}_{1}$, the best process of enantiopurification consists in adding solvent $V_{1}$ in order to place the overall composition into the two-phase region (region 3 if enantiomer $S$ is concerned). A new equilibrium is then established between $\langle\mathrm{S}>$ and the mother liquor (point $\mathrm{K}$ ). Then, a selective crystallization using an appropriate cooling program can be used to obtain the desired enantiomer.

Depending on the location of $I_{1}$ and $K$, the maximum mass of pure enantiomer $<S>$ that can be recovered is given by:

$$
\mathrm{m}<\mathrm{S}>=\mathrm{m}_{\mathrm{T}} \times \frac{\mathrm{KI}_{1}}{\mathrm{SI}_{1}}
$$

with $\mathrm{m}_{\mathrm{T}}$, the total mass.

Obviously, this mass is always lower than the total mass of enantiomeric excess since e.e. $\left(\mathrm{I}_{1}\right) \neq 0$.

It is then possible to proceed to a recrystallization of a pure enantiomer in the case of a racemic compound-forming system. However, this is only applicable to a starting system presenting a sufficient enantiomeric excess. Thus, the process requires a first enrichment step that can be performed by chiral chromatography or via diastereoisomer formation. Moreover, it is not possible to recover the totality of the enantiomeric excess.

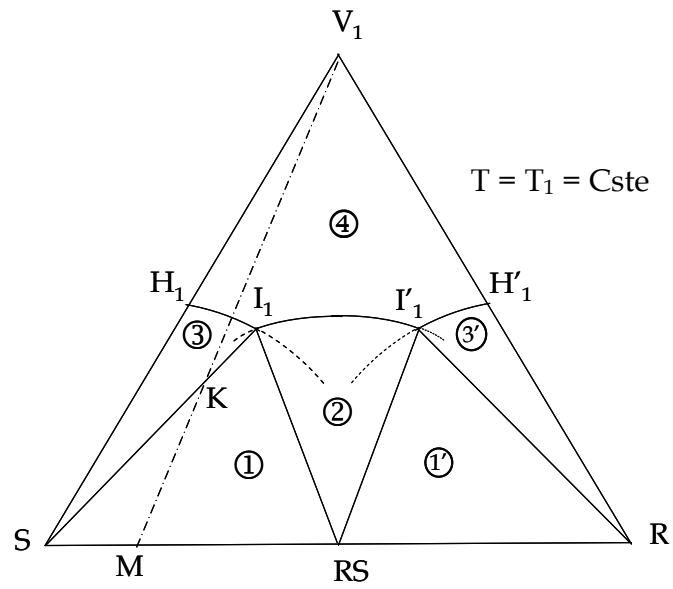

Triphasic domains

Region 1 : Invariant liquid $\mathrm{I}_{1}$ doubly saturated $+\langle\mathrm{S}\rangle+\langle\mathrm{RS}\rangle$

Region $1^{\prime}$ : Invariant liquid $\mathrm{I}_{1}^{\prime}$ doubly saturated $+<\mathrm{R}>+<\mathrm{RS}>$

Biphasic domains:

Region 2: Saturated solution $+<\mathrm{RS}>$

Region 3: Saturated solution $+<\mathrm{S}>$

Region 3': Saturated solution $+<\mathrm{R}>$

Monophasic domain:

Region 4: Undersaturated solution

Fig. 3. Ternary phase diagram observed for a racemic compound-forming system 


\subsection{Enantiopurification from a conglomerate-forming system}

On figure 4 is depicted the ternary phase diagram observed for a conglomerate forming system ( $\mathrm{S}$ and $\mathrm{R}$ enantiomers, solvent $\mathrm{V}_{1}$ ) at temperature $\mathrm{T}_{1}$. This diagram is simpler that the one corresponding to the racemic compound-forming system since only two solid phases ( $\mathrm{S}$ and R) can coexist. Four regions are delimited by the solubility curves (see legend of figure 4).

Here, as for the racemic compound, starting from a mixture $M$ of enantiomers, the process consists in adding the exact quantity of solvent ( $\left.a t \mathrm{~T}_{1}\right)$ so that the overall synthetic mixture is represented by point $\mathrm{K}$. Point $\mathrm{K}$ is situated on the tie-line SI separating the 3 phase domain IS-R (which contains: pure $\langle\mathrm{S}\rangle$, pure $\langle\mathrm{R}\rangle$ and the doubly saturated solution I) and the biphasic domain S-H-I (where the phases in equilibrium are pure $\langle\mathrm{S}\rangle$ and the saturated solution). Then the selective crystallization can be pursued.

Contrary to the previous case, the whole enantiomeric excess of mixture $\mathrm{M}$ can be retrieved (on the condition that the compound crystallizes as a conglomerate without partial solid solution). It constitutes the best situation to obtain an efficient recrystallization in thermodynamic equilibrium.

In practice (see figure 5), it is better to heat the system above $T_{1}$ so that the suspension at $\mathrm{T}_{2}>\mathrm{T}_{1}$ contains only pure $<\mathrm{S}>$ and a saturated solution. The smooth cooling program will mainly consist in crystal growth leading to a better filterability and a more efficient washing of the filtration cake.

It is even sometime possible to retrieve more than the initial enantiomeric excess by cooling the system at $T_{0}$. Point $K$ is then situated in the 3-phase domain and as long as the crystallization is stereoselective the liquid composition can evolve from $I_{1}$ at $\left(T_{1}\right)$ to $Z_{0}$ at $T_{0}$ (figure 6). Note that $Z_{0}$ is located on the metastable solubility curve of $S$ at $T_{0}$. This corresponds to an "entrainment" (i.e. a single operation of the so-called AS3PC process).

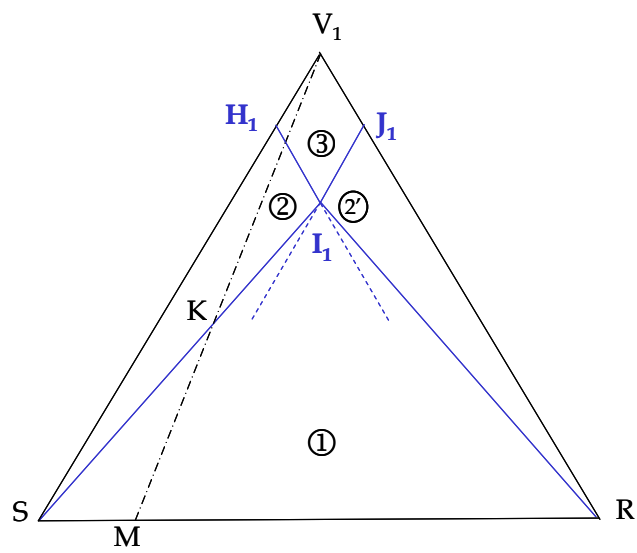

Triphasic domain: 1 - Invariant liquid I doubly saturated $+\langle\mathrm{S}\rangle+\langle\mathrm{R}\rangle$

Biphasic domains: 2 - Saturated solution $+\langle\mathrm{S}\rangle ; 2^{\prime}-$ Saturated solution $+\langle\mathrm{R}\rangle$

Monophasic domain: 3 - Undersaturated solution

Dashed lines stand for metastable solubilities

Fig. 4. Ternary phase diagram observed for a conglomerate forming system 


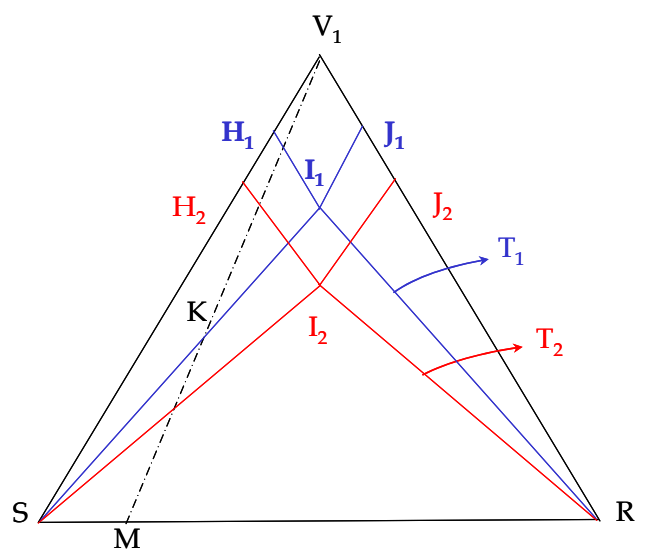

Fig. 5. Ternary phase diagrams observed for a conglomerate-forming system at $\mathrm{T}_{1}$ (Blue) and $\mathrm{T}_{2}$ (Red)

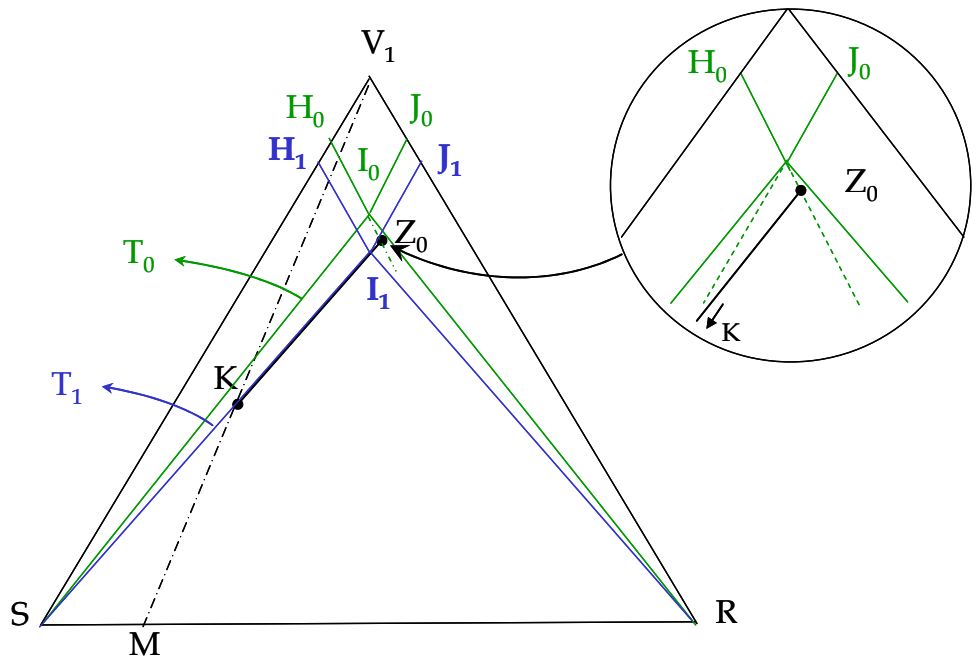

Fig. 6. Principle of crystallization by entrainment

When the initial mixture $M$ corresponds already to a high enantiomeric excess, solvent $V_{1}$ at temperature $\mathrm{T}_{1}$ won't be appropriate because the slurry will be simply much too viscous. Thus, it is necessary to find another solvent $V_{2}$ in which the pure enantiomer $\langle\mathrm{S}\rangle$ is poorly soluble (figure 7).

\subsection{Enantiopurification from conglomerate-forming derivatives}

Figure 8 shows that a conglomerate-forming solvate (here a monohydrate) can also give the full discrimination in the solid state even if a stable racemic compound exists for the anhydrous chiral components. The enantiopurification by means of crystallization can be operated in a similar way as that presented above (point $\mathrm{K}$ for a mixture $\mathrm{M}$ at $\mathrm{T}_{1}$ ). When the 
initial point $\mathrm{M}$ is close to the pure enantiomer (e.g. S), the medium can be changed by mixing an anti-solvent. The second solvent must be miscible with water, should not induce a miscibility gap and should not inhibit the formation of the conglomerate.

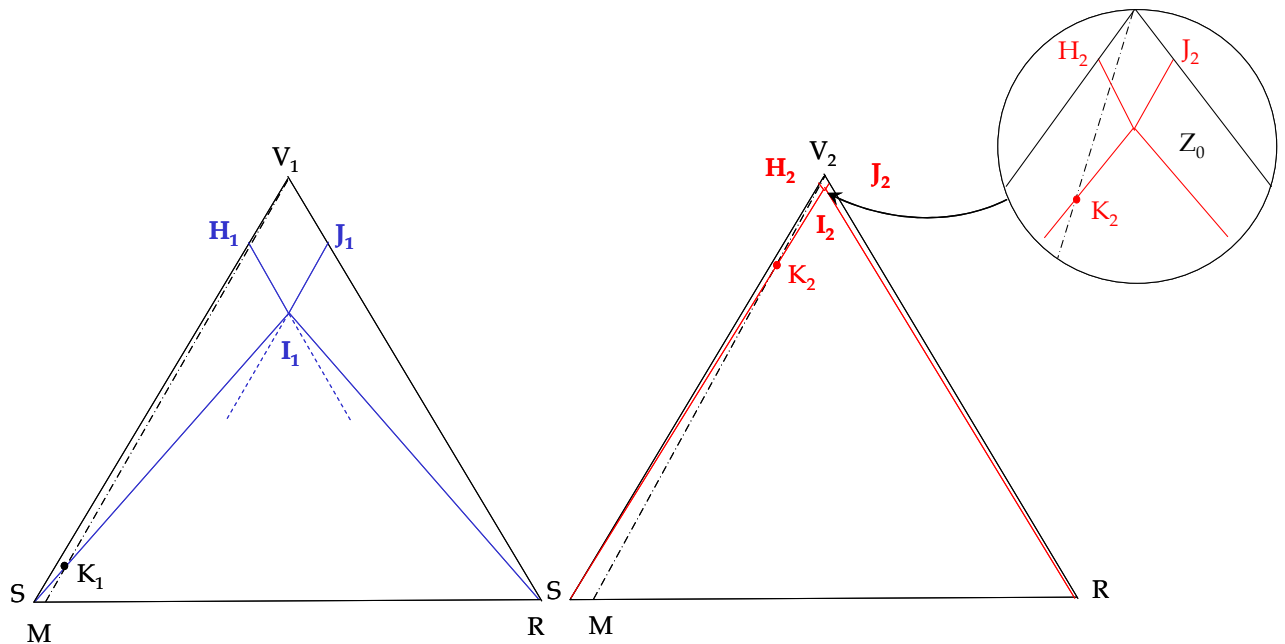

Fig. 7. Enantiomeric purification with a high enantiomeric excess - Choice of another solvent

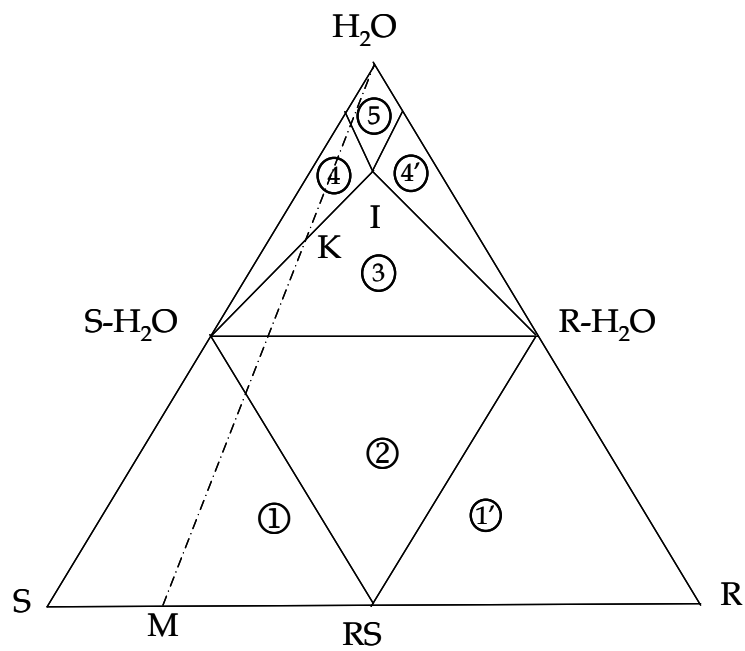

$\left.1:\left\langle\mathrm{S}-\mathrm{H}_{2} \mathrm{O}\right\rangle+\langle\mathrm{S}\rangle+\langle\mathrm{RS}\rangle ; 1^{\prime}:\left\langle\mathrm{R}-\mathrm{H}_{2} \mathrm{O}\right\rangle+\langle\mathrm{S}\rangle+<\mathrm{RS}\right\rangle$

2: $\left\langle\mathrm{S}-\mathrm{H}_{2} \mathrm{O}>+<\mathrm{R}-\mathrm{H}_{2} \mathrm{O}>+<\mathrm{RS}>\right.$

3: Invariant liquid I doubly saturated $+\left\langle\mathrm{S}-\mathrm{H}_{2} \mathrm{O}\right\rangle+\left\langle\mathrm{R}-\mathrm{H}_{2} \mathrm{O}\right\rangle$

4: Saturated solution $+\left\langle\mathrm{S}-\mathrm{H}_{2} \mathrm{O}\right\rangle$

$4^{\prime}$ : Saturated solution $+<\mathrm{R}-\mathrm{H}_{2} \mathrm{O}>$

5: Undersaturated solution

Fig. 8. Enantiomeric purification from a derivative (case of a monohydrate) 


\subsection{Benefits of conglomerate}

It is now obvious that proceeding to the enantiopurification with a starting product crystallizing as a conglomerate is even more beneficial since:

- an optimized recrystallization can 'virtually' be carried out without any loss of enantiomeric excess which is not possible with a racemic compound.

- the choice of appropriate solvent and crystallization conditions usually allows to reach an e.e greater than $99.5 \%$.

- an optimized recrystallization can be carried out on derivatives such as hydrates (crystallizing as conglomerates) even if the molecule of interest crystallizes as a stable racemic compound.

Note also, that when coupled to racemization, almost pure enantiomer can be obtained by attrition from the racemic mixture (Levillain et al, 2009).

\section{Detection of conglomerate}

To perform preferential crystallization, the racemic mixture should crystallize as a stable conglomerate. In most cases, the chiral resolution can not be envisaged on the original compound because it does not fulfill this condition. An interesting alternative is to proceed to the resolution on derivatives such as salts, co-crystals, hydrates or solvates that crystallize as conglomerates (at the end of the resolution process, the pure enantiomer can be easily recovered by salting out, dehydration or desolvation). To multiply the chances of spotting a conglomerate, experiments have to be performed on a large number of non chiral acids (for a chiral base) with various stoichiometries and solvents, with different co-crystal formers and under various crystallization conditions.

Consequently, starting from the racemic mixture it is often necessary to synthesize series of derivatives that have to be analyzed in order to isolate at least one conglomerate forming system. Due to the low occurrence of conglomerates, it usually implies to investigate a large number of derivatives.

Conglomerate detection which is an essential step of the resolution method can be pursued by various methods which are described and discussed in the following.

\subsection{Classical screening of conglomerates}

\subsubsection{Comparisons between IR, Raman, solid state NMR or XRPD patterns}

Several spectroscopic techniques can be used to differentiate the racemic mixture and the conglomerate via comparison between the racemic pattern and that of the enantiomer. In case of conglomerate without partial solid solution, the patterns of the pure enantiomer obtained from IR, Raman, solid state NMR or XRPD should be superimposable to the ones obtained for the racemic mixture.

Even if Raman spectroscopy and IR spectroscopy can be of a certain help in spotting a conglomerate, they cannot be considered as totally reliable. Indeed, vibrational bands mainly arise from molecular vibrations. Only low frequency vibrations are directly related to the vibrations of the crystal lattice. If the neighborhood of a given molecule can generate 
variations in the high frequency domain, two close structures can generate similar spectra. Considering these elements, the perfect match of the XRPD patterns is surely the most dependable way to conclude on the conglomerate nature of a sample. XRPD is of particular interest as it also permits to check the crystallinity of the sample and to spot partial or total solid solutions (Wermester et al, 2007; Renou et al, 2007). Moreover, if a single crystal of sufficient size is available, a structure can be resolved by single crystal X-Ray diffraction. The knowledge of the crystal structure definitively confirms the conglomerate nature (or not) of the sample.

\subsubsection{Alternatives methods}

Other methods consist of isolating a unique particle (single crystal) from the racemic mixture to proceed to the analysis. This particle can be dissolved in a nematic phase (Jacques et al, 1994) or analyzed by chromatography (Chiral CG, HPLC) (Pirzada et al, 2010) and/or polarimetry. However, there are serious limitations to these techniques since the collection of an isolated particle can be difficult and also because the analysis of a single particle necessitates high detection levels. To be exhaustive, let us also mentioned that the detection of a conglomerate can also be performed via thermal analysis (the construction of the binary phase diagram by simple measurements of the melting temperatures of the enantiomers and that of their corresponding racemic mixture can be used to identify the nature of the sample (conglomerate or racemic compound)(Neau et al, 1993) or Solid state circular dichroïsm (SSCD) and CD microscopy (Kuroda et al, 2000; Claborn et al, 2003). The construction of a ternary isotherm is also a reliable method especially when a conglomerate of solvated phases is suspected.

\subsection{High throughput technique for conglomerate prescreening}

Unfortunately and despite technical improvements, all the previous methods are time consuming and often require the pure enantiomer to be available at an early stage of the process. Consequently, there is a need for a faster (and cheaper) method compatible with a combinatorial approach of crystallization derivatives (salts, hydrates, solvates, cocrystals, etc.)

Considering the data summarized in table 1, it appears that racemic compounds crystallize not often in non centrosymmetric structures (less than $5 \%$ for NA $+\mathrm{NC}$ ). Consequently, a method that would detect the absence of center of symmetry in crystals obtained from racemic mixtures will be able in most cases to detect conglomerates. To this purpose, nonlinear optics can be very useful. In the next paragraphs are presented the theory of second harmonic generation in crystals and described the principle of conglomerate prescreening.

\subsubsection{Nonlinear optics and second harmonic generation (SHG)}

In a given medium, the propagation of light is mainly driven by the dielectric properties and the response to electromagnetic fields. The application of an electromagnetic field (light) to a molecule modifies the shape of the electronic cloud and consequently creates an induced electric dipole moment. 
The term polarization ( $\mathbf{P}$, vectorial dipole moment per unit volume) is used to describe this phenomenon on a macroscopic scale:

$$
\mathbf{P}=\varepsilon_{0} \chi^{(1)} \mathbf{E}
$$

with $\mathbf{E}$, the applied electric field, $\varepsilon_{0}$ is the vacuum permittivity and $\chi^{(1)}$ the linear (first order) susceptibility of the material.

The linear susceptibility is a $2^{\text {nd }}$ rank tensor related to the permittivity $\varepsilon$ and the refractive index $\mathrm{n}$ of the material:

$$
\varepsilon=\mathrm{n}^{2}=\varepsilon_{0}\left(1+\chi^{(1)}\right)
$$

For week electric fields, the polarization varies linearly with E. However, for high light intensities (typically greater than $1 \mathrm{MW} / \mathrm{cm}^{2}$ ), the polarization becomes a nonlinear function of the applied electric field. It can be expressed as a power series expansion of the macroscopic field:

$$
\mathbf{P}=\varepsilon_{0}\left(\chi^{(1)} \mathbf{E}+\chi^{(2)} \mathbf{E}^{2}+\chi^{(3)} \mathbf{E}^{3}+\ldots\right)=\varepsilon_{0} \chi^{(1)} \mathbf{E}+\mathbf{P}_{\mathrm{NL}}
$$

with $\chi^{(2)}$ and $\chi^{(3)}$ the second and the third order susceptibility tensors respectively and $\mathbf{P}_{\mathrm{NL}}$, the nonlinear polarization. This equation implies that during the propagation of light at a frequency $\omega$, nonlinear components of the polarization at frequencies $2 \omega$ and $3 \omega$ arise and harmonics of the original optical field at $2 \omega$ and $3 \omega$ are generated. However, with increasing order, a rapid decrease in the susceptibility coefficients is observed. As a consequence, the nonlinear polarization $\mathbf{P}_{\mathrm{NL}}$ can be approximated by the quadratic term $\varepsilon_{0}$ $\chi^{(2)} \mathbf{E}^{2}$ for moderate energies. Considering the usual expression of the electromagnetic field

$$
\mathbf{E}=\frac{1}{2} \mathbf{E}_{\mathbf{0}} \exp [\mathrm{j}(\omega \mathrm{t}-\mathbf{k . r})]+\mathrm{c.c}
$$

with $\mathbf{E}_{\mathbf{0}}$, the amplitude and $\mathrm{k}$ the wave vector and c.c, the complex conjugate of the formula. the polarization then becomes equal to:

$$
\left.\begin{array}{c}
\mathbf{P}=\varepsilon_{0} \chi^{(1)} \mathbf{E}+\varepsilon_{0} \chi^{(2)} \mathbf{E}^{2} \\
\mathbf{P}=\frac{1}{2}\left\{\begin{array}{l}
\varepsilon_{0} \chi^{(2)} \mathbf{E}_{0}^{2} \\
+\varepsilon_{0} \chi^{(1)} \mathbf{E}_{\mathbf{0}} \exp [\mathrm{j}(\omega \mathrm{t}-\mathbf{k} . \mathbf{r})] \\
+\frac{1}{2} \varepsilon_{0} \chi^{(2)} \mathbf{E}_{\mathbf{0}}^{2} \exp [2 \mathrm{j}(\omega \mathrm{t}-\mathbf{k} . \mathbf{r})
\end{array}\right]
\end{array}\right\}
$$

Finally, the net polarization is composed of three components: a continuous one corresponding to the phenomenon of optical rectification, a component at frequency $\omega$ (optical polarizability) and a second harmonic term (frequency $2 \omega$ ) corresponding to the phenomenon known as SHG (second harmonic generation). In SHG, a fundamental wave of amplitude $\mathbf{E}_{\omega}$, angular frequency $\omega$ (wavelength $\lambda$ ) and wave vector $\mathbf{k}_{\boldsymbol{\omega}}$ passing through a crystal generates a second harmonic wave of amplitude $E_{2 \omega}$, angular frequency $2 \omega$ (wavelength $\lambda / 2$ ) and wave vector $\mathbf{k}_{2 \omega}$. 


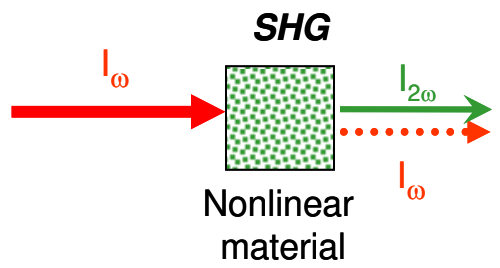

Fig. 9. Second harmonic generation

With distance traveled through the crystal, the second harmonic amplitude varies. The energy generated at frequency $2 \omega$ can be obtained by solving the propagation equation:

$$
\nabla^{2} \mathbf{E}-\mu_{0} \varepsilon_{0} \frac{\partial^{2} \mathbf{E}}{\partial \mathbf{t}^{2}}=\mu_{0} \frac{\partial^{2} \mathbf{P}}{\partial \mathbf{t}^{2}}
$$

with $\mu_{0}$, the permeability of free space.

The average intensity of an electromagnetic wave of amplitude $\mathbf{E}$ is:

$$
I=\frac{\mathbf{E} \cdot \mathbf{E}^{*}}{2 \varepsilon_{0} \mathrm{C}}
$$

with $\mathrm{c}$, the velocity of light. Assuming that the waves are traveling in the $\mathrm{z}$ direction and that the conversion efficiency is low (so amplitude of the fundamental is almost unchanged), the second harmonic intensity after a distance $\ell$ through the crystal is (Armstrong, 1962):

$$
\mathrm{I}_{2 \omega}(\ell)=\frac{\omega^{2}\left(\chi^{(2)}\right)^{2} \ell^{2}}{2 \varepsilon_{0} \mathrm{c}^{3} \mathrm{n}_{\omega}^{2} \mathrm{n}_{2 \omega}} \frac{\sin ^{2}\left(\frac{\Delta \mathrm{k} \ell}{2}\right)}{\left(\frac{\Delta \mathrm{k} \ell}{2}\right)^{2}} \mathrm{I}_{\omega}^{2}
$$

with :

$\mathrm{n}_{\omega}$, the refractive index of the crystal at angular frequency $\omega$

$\mathrm{n}_{2 \omega}$, the refractive index of the crystal at angular frequency $2 \omega$

$\Delta \mathrm{k}$, the phase mismatch: $\Delta \mathrm{k}=\mathrm{k}_{2 \omega}-2 \mathrm{k}_{\omega}=\frac{2 \omega}{\mathrm{c}}\left(\mathrm{n}_{2 \omega}-\mathrm{n}_{\omega}\right)$;

$\mathrm{I}_{2 \omega}$ depends on several parameters and among them on the value of $\Delta \mathrm{k}$. The case of $\Delta \mathrm{k}=0$ corresponds to materials called "phase-matchable materials" for which the longer the distance traveled inside the crystal, the greater the SHG intensity (i.e. large particles will generate a better SHG signal). Phase-matchable materials such as potassium diphosphate (KDP) are used to double high power lasers or as a nonlinear standard. But most materials are "non phase-matchable" (ie. $\Delta \mathrm{k} \neq 0$ ) with as a consequence an intensity value oscillating with $\ell . I_{2 \omega}$ will reach a maximum only for the discrete values of $\ell$ given by: 


$$
\ell_{\mathrm{c}}=\frac{\pi}{\Delta \mathrm{k}}=\frac{\lambda}{4\left(\mathrm{n}_{2 \omega}-\mathrm{n}_{\omega}\right)}
$$

$\ell_{\mathrm{c}}$ is called the "coherence length".

This implies that the SHG intensity will be optimized for particles of size equal to $\ell_{\mathrm{c}}$ or equal to an odd multiple of $\ell_{\mathrm{c}}$. The consequence of the coherence length will be discussed later. $\mathrm{I}_{2_{\omega}}$ depends also on $\chi^{(2)}$, the second order nonlinear susceptibility, and this is the main point for the detection of conglomerates. 27 numbers constitute the electro-optic components of $\chi^{(2)}$ which is a $3^{\text {rd }}$ rank tensor. However, the number of independent coefficients can be reduced to 10 if the absorption of the material is negligible at $\omega$ and $2 \omega$. In this case, the tensor is invariant by circular permutation of its three indices.

Moreover, the number of independent coefficients non equal to zero can be determined by tacking into account the symmetry elements of the 32 crystallographic classes. In particular, all the components of $\chi^{(2)}$ are null for centrosymmetric structures. Thus, in crystals with a centre of inversion, all the components of $\chi^{(2)}$ tensor are zero. Consequently, these types of crystals can not exhibit a SHG signal. According to the Kleinman symmetry rules (Kleinman, 1962) three chiral point groups (NC) present also a null $\chi^{(2)}(422,622$ and 432). However, Kleinman symmetry is not always applicable. These different possibilities are summarized in figure 10.

As a result, the absence of a center of symmetry can be determined via the detection of a SHG signal. Therefore, this test was chosen as a pre-screening method for spotting conglomerates.
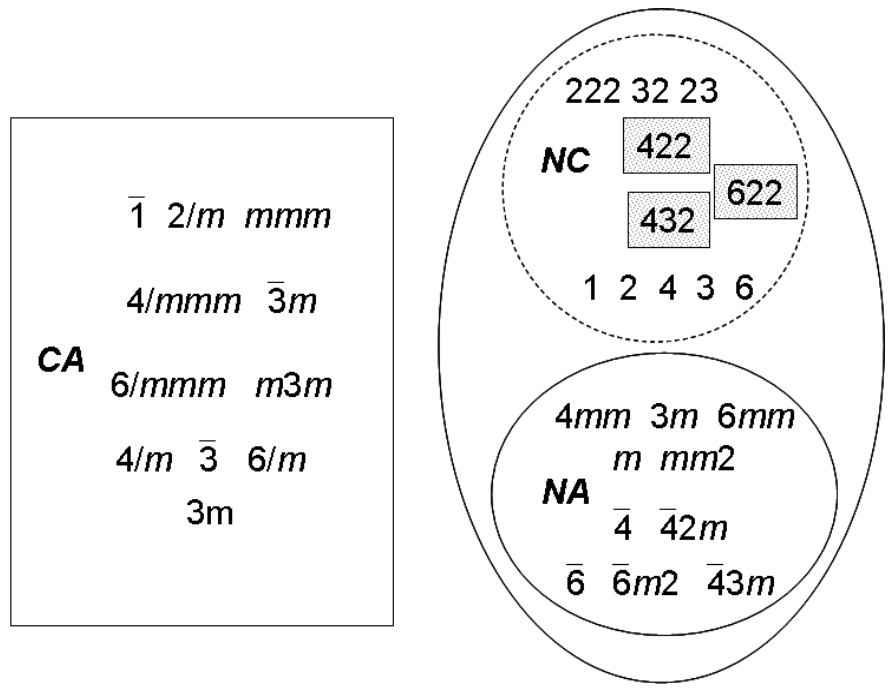

$\square$ : centrosymmetric point groups (no SHG activity)

$0:$ non centrosymmetric point groups (SHG activity)

: : no SHG activity if Kleinman symmetry is applicable

Fig. 10. SHG activity among the 32 crystallographic classes 


\subsubsection{Experimental set-up}

The experimental set up proposed by Kurtz and Perry (Kurtz et al, 1968) gives quick information about the SHG activity of powder samples. Because the majority of the pharmaceutical crystalline samples are available in the form of powders, this set-up was chosen for the pre-detection of conglomerates.

Figure 11, shows the experimental set-up used for the SHG test. The laser is a Nd:YAG Qswitched laser operating at $1.06 \mu \mathrm{m}$. It delivers $360 \mathrm{~mJ}$ pulses of $5 \mathrm{~ns}$ duration with a repetition rate of $10 \mathrm{~Hz}$. An energy adjustment device is made up of two polarizers $(\mathrm{P})$ and a half-wave plate $(\lambda / 2)$.

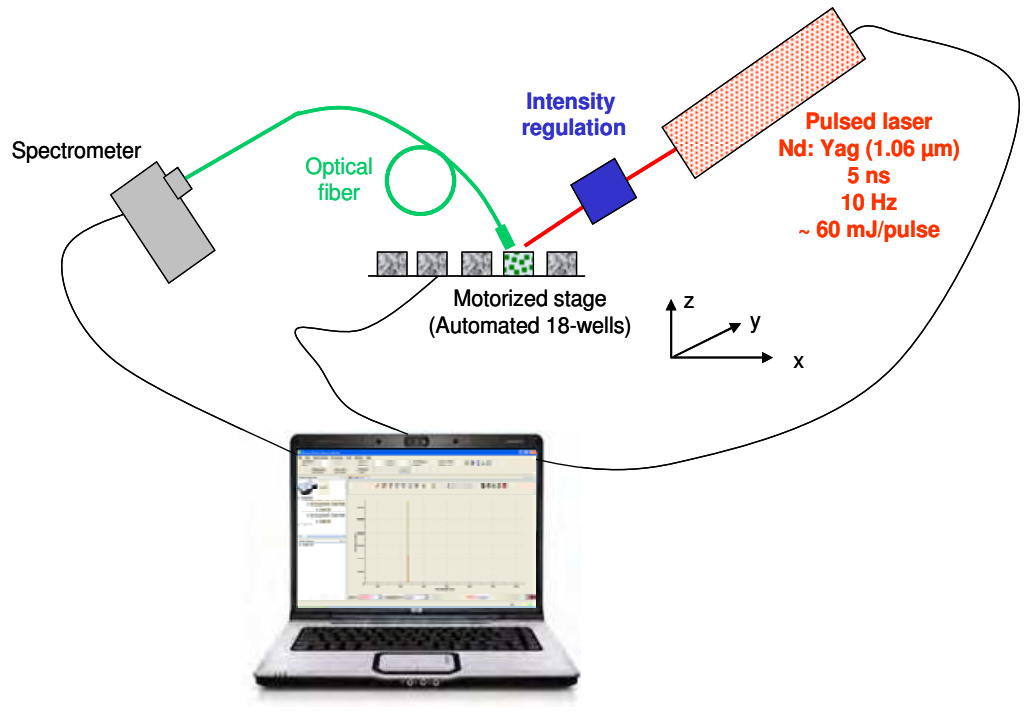

Fig. 11. Experimental Set-up

It allows the incident energy to vary from 0 to circa $200 \mathrm{~mJ}$ per pulse. A RG1000 filter is situated after the energy adjustment device to removes light from laser flash lamps. The samples (18-wells plate filled with the various powders) are placed on a motorized stage and irradiated with $60 \mathrm{~mJ}$ pulses (beam diameter of $4 \mathrm{~mm}$ ). The signal generated by the sample (diffused light) is collected into an optical fiber $(500 \mu \mathrm{m}$ of core diameter) and directed onto the entrance slit of a spectrometer. A boxcar integrator allowed an average spectrum (spectral range $250-700 \mathrm{~nm}$ with a resolution of $\pm 0.2 \mathrm{~nm}$ ) to be recorded over 1 second (10 pulses).

\subsubsection{Accuracy of the SHG method}

Because of the low occurrence of conglomerates, it would be extremely detrimental to fail to spot one. Conversely, it is not awkward to have a limited number of false positive responses. The diagram presented on figure 12 gathers the various situations that can be encountered during the SHG prescreening. It can be used to evaluate the consistency of the SHG response observed for a given sample. 
(a) Signal detected at $\lambda / 2$

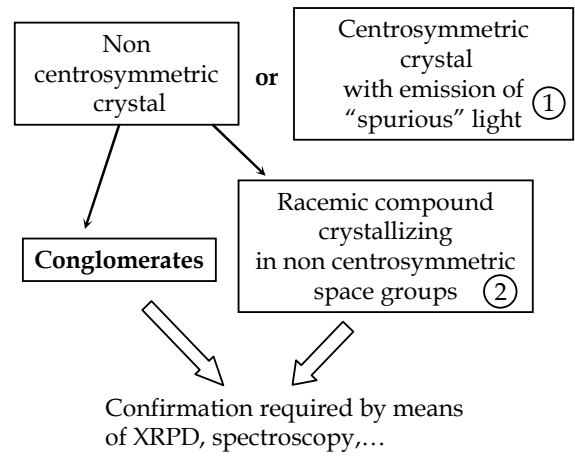

(b) No signal detected at $\lambda / 2$

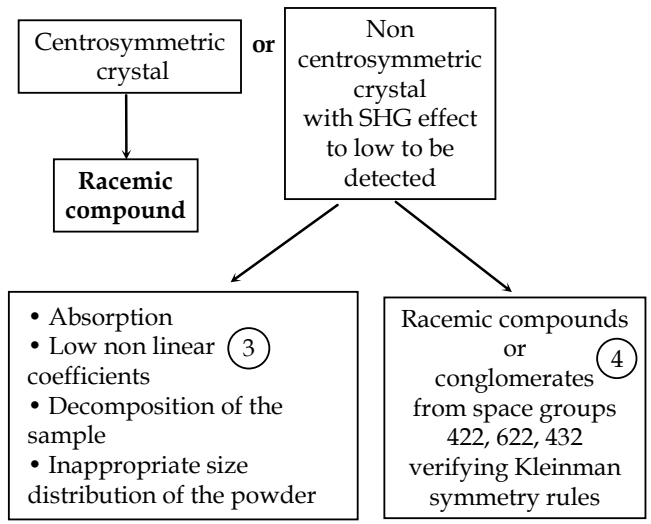

Fig. 12. Decision diagram for SHG test

Panel (a) of the diagram corresponds to the samples for which a signal has been observed. It is necessary to distinguish between two cases: (1) the observation of a "non SHG" signal resulting from optical phenomena such as two-photon fluorescence (TPF) or other photoluminescent processes and (2) the observation of a "real SHG" signal resulting from racemic compounds crystallizing in non-centrosymmetric space groups.

False positive response arising from case 1 can be simply encountered. Indeed, TPF signals present a spectral bandwidth much broader than that of the SHG signal (cf. figure 13).

A base line correction around the SHG wavelength allows the distinction between light resulting from the SHG process itself (signal of interest) and "spurious" light. This simple procedure strongly limits the occurrence of false positive responses.
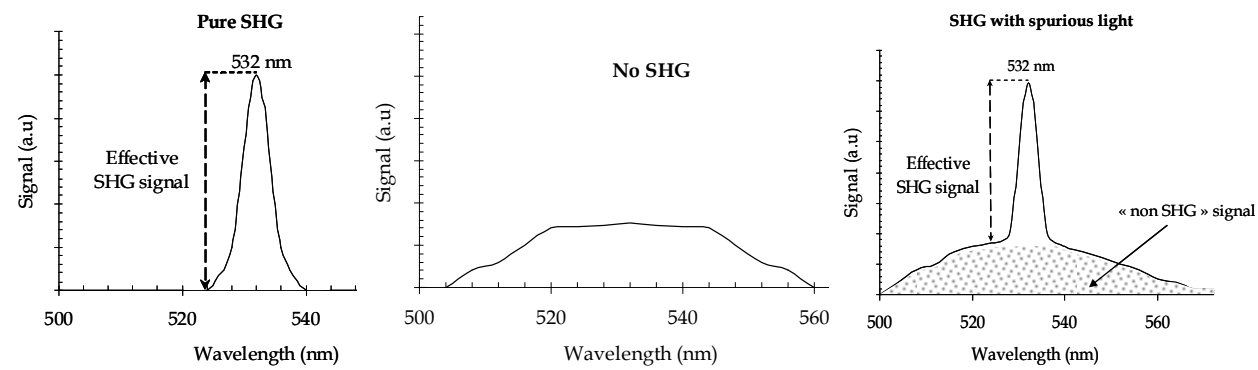

Fig. 13. Removal of false positive responses

As mentioned in table 1, it is possible for a racemic mixture to crystallize in a noncentrosymmetric space group. These types of crystals generate a SHG response and can also be considered as false positive. They constitute case 2. It is also worth mentioning that slightly disordered racemic structures and solid solutions can fall in this category. The influence of the degree of disorder (or pseudo-symmetry) of the structure is difficult to 
establish so as the consequences on the $\chi^{(2)}$ coefficients. However, the detection of partial solid solutions can be of interest since some of them can be potentially adequate for preferential crystallization (Wermester et al, 2007).

Panel (b) of the diagram concerns samples that do not present any signal at $\lambda / 2$. The critical situation of non detected conglomerates is considered in case 3 . The main reasons of the "nodetection" are an SHG effect too weak to be detected (due to for example to low non linear coefficients consequence of a low hyperpolarizability of the molecule) or an inappropriate crystal size distribution. The second harmonic signal generated by a crystalline powder is the sum of the contribution of each individual particle (electromagnetic fields are uncorrelated). Because the fundamental beam passes through a large number of particles for which a random orientation is assumed, the intensity of the SHG beam is not easy to optimize and depends on the particle size (especially in non phase matchable materials). To preserve the reliability of the method, too fine particles as those present in submicronic or nanocrystalline powders should be avoided (coherence length is in order of magnitude of several microns for most materials). To limit the number of undetected conglomerates, it is also necessary for the experimental setup to present a detection level better than 1/100 of the SHG signal generated by the quartz powder (standard non phase-matchable material for SHG measurements - mean diameter 50 $\mu \mathrm{m})$. This condition is in most cases considered as sufficiently constraining. To be exhaustive, let us mentioned that a non detectable (or a decreasing) signal can also be the consequence of an absorption in the sample at the wavelength of irradiation $(\lambda)$ or at the wavelength of the reemitted radiation $(\lambda / 2)$. This absorption can generate a decomposition of the sample when exposed to the laser beam. The use of an alternative laser source must then be envisaged.

The last case (Case 4) concerns chiral crystals associated to point groups 422, 622 and 432. These should be SHG inactive due to the application of Kleinman permutation rules. However, experience refutes the general applicability of these rules. Recently, SHG activity has been observed in $\mathrm{N}$-acetyl-methylbenzylamine which crystallizes as a conglomerate in space group $\mathrm{P} 4{ }_{1} 2{ }_{1} 2$.

Considering all these elements, spotting a SHG active substance can not guaranty the existence of a conglomerate. Only a complementary study of the samples by conventional methods can conclude on the conglomerate nature or not. That is why this method is proposed as a prescreening technique only. However, SHG presents numerous benefits listed below:

- $\quad$ Only a small quantity of the racemic mixture is necessary (ca. 20 mg typically).

- There is at this first stage of pre-screening no need for comparison between results of SHG tests on the racemic mixture and the pure enantiomer. The screening can be undertaken even when the pure enantiomer is not available and thus be carried out at an early stage of the development of the molecule.

- The response is instantaneously delivered; it is thus conceived to be a true high throughput pre-screening method which allows on a short period of time to test numerous derivatives.

- It is a priori a non destructive method.

- It is cheap and can be fully automated: a high throughput device including motorized sample holders and a computer assisted treatment of the spectra should allow in a realistic way to select the "good" candidates with a $50 \%$ probability or more. 


\subsection{Rationalization of conglomerate detection}

When a positive SHG signal is obtained, the conglomerate nature of the compound has to be confirmed via XRPD. However, it is worth mentioning that some bias in the conglomerate detection can be introduced at this stage if a strict control of the crystallization conditions is not applied. To avoid misinterpretation of the results, the diagram of figure 14 is proposed for an optimization of conglomerate detection (Gonella, 2011).

Once the SHG prescreening has led to suspect the existence of a conglomerate (step 1 completed), the next step consists in comparing the XRPD patterns of the racemic mixture and the corresponding enantiomer. At this stage it is imperative to apply the same crystallization conditions for the two samples to avoid discrepancies due to polymorphism or solvation / desolvation. It concerns in particular the nature of the counter-ion or cocrystal former, the stoichiometry, the temperature (during the crystallization but also during the SHG detection), the nature of the solvent, etc.

Once both compounds are available (step 2), a precise comparison of the XRPD patterns can be pursued.

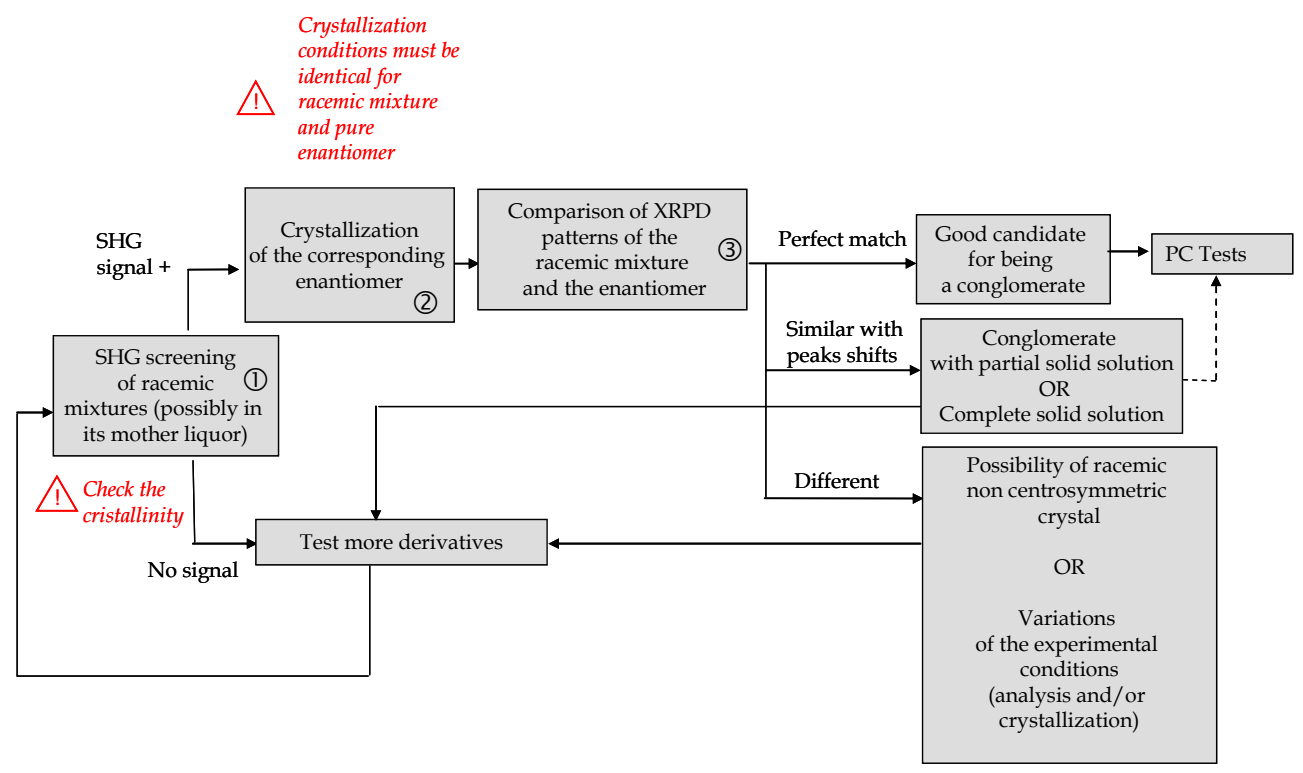

Fig. 14. Workflow for conglomerate detection

Three different cases can be encountered on step 3 : perfect match, similar diffractograms with some peak shifts or different diffractograms). On Figure 15 are presented the XRPD patterns obtained for three different compounds. The upper traces correspond to the racemic mixture (1a, 2a, 3a) and the lower ones to the pure enantiomer $(1 b, 2 b, 3 b)$.

Diffractograms 1a and $1 \mathrm{~b}$ perfectly match which permits to conclude that compound 1 is with a high level of confidence a conglomerate. PC tests can be undertaken. Diffractograms $2 \mathrm{a}$ and $2 \mathrm{~b}$ present numerous differences. Compound 2 is unlikely to be a conglomerate 

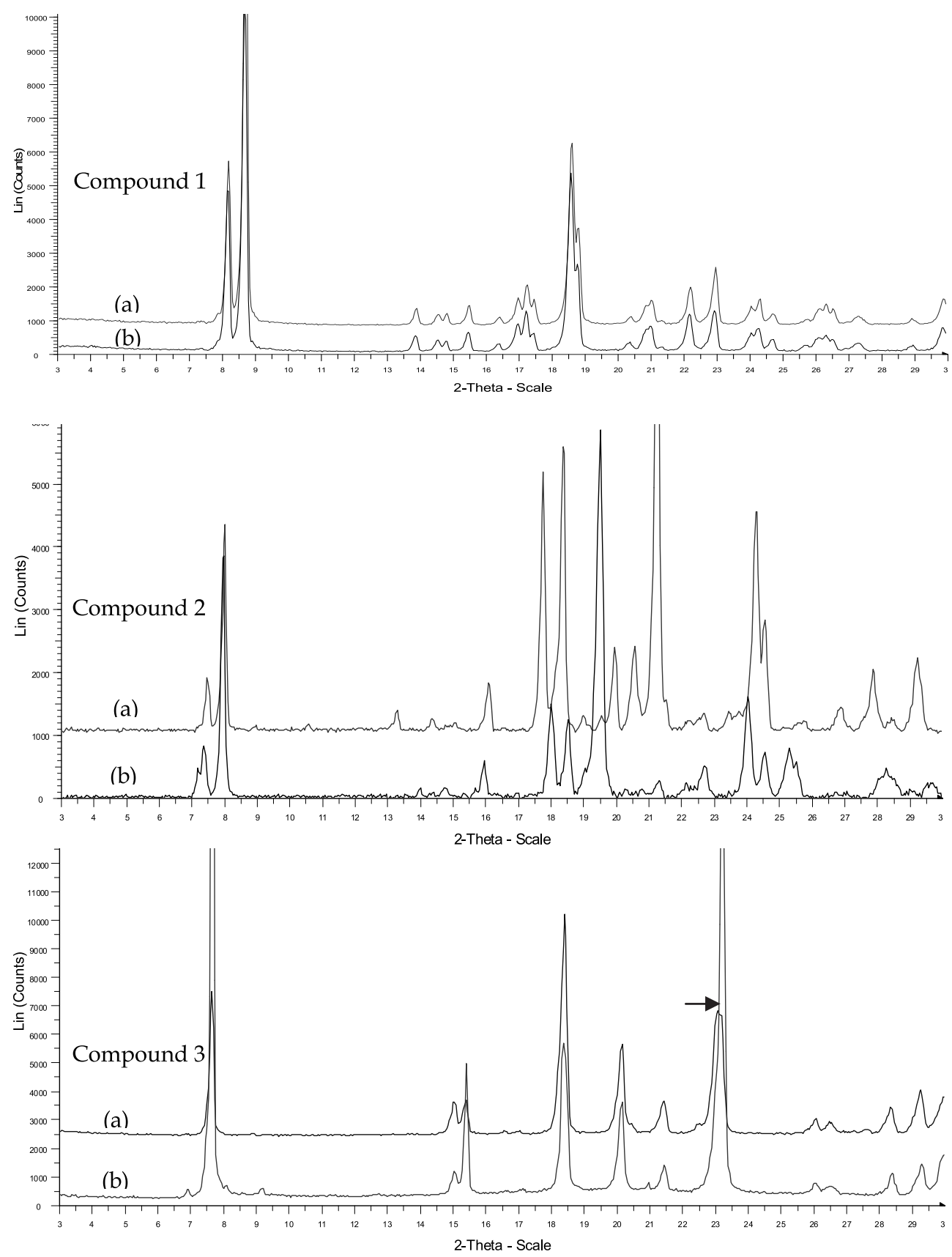

Fig. 15. Comparison of X-Ray patterns for the detection of conglomerate 
forming system. However, it is worth mentioning that interesting conglomerates may exist only in equilibrium with their mother liquor (because of one or several of the following reasons: non congruent solubility, solvates with an efflorescent character, solvates which are hydrolyzed by moistures, $\mathrm{CO}_{2}$ sensitive solid, etc). So it is of primary importance to check if the conditions used during the SHG test are identical to those used for XRPD. Indeed, due to the quickness of the SHG test, an efflorescent solvate could be detected as a conglomerate. Its desolvation prior or concomitantly to the XRPD analysis could then lead to contradictory results. To overcome these problems, SHG and XRPD tests should be run under strictly identical conditions of crystallization.

Diffractograms $3 \mathrm{a}$ and $3 \mathrm{~b}$ are extensively similar but show slight shifts in $2 \theta$ positions of some peaks. This couple of derivatives deserves more investigations. Nevertheless, it is likely that this system exhibits at least partial solid solutions.

\section{Conclusion}

The objective of this chapter was a better understanding of chiral discrimination in the solid state and of the mechanisms involves during recrystallization of enantiomers.

We described two methods of enantiopurification and underlined the benefits of preferential crystallization. Because the detection of a conglomerate is an essential step of this process, we detailed a recently developed technique of prescreening of conglomerates. We finally proposed a workflow to follow in order to optimize the detection of conglomerates and avoid bias that can be induced by different crystallization parameters.

\section{References}

Armstrong, J. A., Bloembergen, N., Ducuing, J., \& Pershan, P. S. (1962). Interactions between light waves in a nonlinear dielectric. Physical Review, Vol. 127, No. 6, (September 1962), pp. 1918-1939

Belsky, V. K. \& Zorkii, P. M. (1977), Distribution of organic homomolecular crystals by chiral types and structural classes, Acta Crystallographica Section A, Vol. 33, No. 6, (November 1977), pp. 1004-1006, ISSN 1600-5724

Brock, C. P., Schweizer, W. B., \& Dunitz, J. D. (1991), On the validity of wallach's rule: on the density and stability of racemic crystals compared with their chiral counterparts, Journal of American Chemical Society, Vol. 113, No. 26, (December 1991), pp. 98119820, ISSN 0002-7863

Claborn, K., Puklin-Faucher, E., Kurimoto, M., Kaminsky, W., \& Kahr, B. (2003), Circular dichroism imaging microscopy:\&nbsp; application to enantiomorphous twinning in biaxial crystals of 1,8-dihydroxyanthraquinone, Journal of the American Chemical Society, Vol. 125, No. 48, (December 2003), pp. 14825-14831, ISSN-0002-7863.

Collet, A. (1999), Separation and purification of enantiomer by crystallization methods, Enantiomer, Vol. 4, No. , (1999), ISSN

Coquerel, G., Petit, M.-N., \& Bouaziz (1995). Method of resolution of two enantiomers by crystallisation. PCT Patent WO 95/08522.

Coquerel, G.; Petit, M.-N.; Bouaziz, R.(1994) Procédé de dédoublement (AS3PC) de deux antipodes optiques par entraînement polythermique programmé et autoensemencé. PCT Nº4/01.107, 22/09/1994, 1994. 
Coquerel, G. (2000), Review on the heterogeneous equilibria between condensed phases in binary systems of enantiomers, Enantiomer, Vol. 5, No. 5, pp. 481-498, (Mai 2000), ISNN 1024-2430

Coquerel, G. (2007). Preferential Crystallization, In : Novel optical resolution technologies Topics in Current Chemistry, Sakai, Kenichi et al (Eds), pp. 1-51, Springer, ISBN 9783-540-46317-7, Berlin.

Dalhus, B. \& Görbitz, C. H. (2000), Non-centrosymmetric racemates: space-group frequencies and conformational similarities between crystallographically independent molecules, Acta Crystallographica Section B, Vol. 56, No. 4, (August 2000), pp. 715-719, ISSN 1600-5740

Flack, H. (2003), Chiral and achiral crystal structures, Helvetica Chimica Acta, Vol.86, No.4, (January 2003), pp. 905-921, ISSN 1522-2675

Flack, H. D. \& Bernardinelli, G. (2003), The mirror of galadriel: looking at chiral and achiral crystal structures, Crystal Engineering, Vol. 6, No. 4, (December 2003) pp. 213-223, ISSN 1463-0184

Galland, A., Dupray, V., Berton, B., Morin-Grognet, S., Sanselme, M., Atmani, H., \& Coquerel, G. (2009), Spotting conglomerates by second harmonic generation. Crystal Growth \& Design, Vol. 9, No. 6, (May 2009), pp. 2713-2718, ISSN 1528-7483

Gernez, D. (1866) Séparation des tartrates droits et des tartrates gauches à l'aide de solutions saturées, Compte-rendus de l'Académie des Sciences, Vol. 63, (July-December 1866), pp. 843-888

Gonella, S., Mahieux, J., Sanselme, M., \& Coquerel, G. (2011). Spotting a conglomerate is just halfway to achieving a preparative resolution by preferential crystallization. Organic Process Research \& Development, In press, ISSN 1083-6160.

Helmreich, M.; Niesert, C.-P.; Cravo, D.; Coquerel, G.; Levilain, G.; Wacharine-Antar, S.; Cardinaël, P, (2010), Process for enantiomeric separation of racemic dihydro-1, 3, 5 triazines via preferential crystallization. PCT patent WO2010109015 (A1), 2010-09-30

Jacques, J., Collet, A., \& Wilen, S. (1994). Enantiomers, Racemates and Resolutions (3rd Edition), Kriger Pub. Co., ISBN 0894-648764, Malabar Florida, USA.

Levilain, G., Rougeot, C., Guillen, F., Plaquevent, J-C., Coquerel, G. (2009) Attrition enhanced preferential crystallization combined with racemization leading toredissolution of the antipode nuclei, Tetrahedron: Asymmetry, Vol. 20, No. 24, (December 2009), pp. 2769-2771, ISSN 0957-4166

Levilain, G., Coquerel, G. (2010) Pitfalls and rewards of preferential crystallization, CrystEngComm, Vol. 12, No. 7, (May 2010), pp. 1983-1992, ISSN 1466-8033

Jungfleish, M. E. (1882), Journal of Pharmaceutical Chemistry, Vol. 5, pp. 346.

Kaptein, B., Elsenberg, H., Grimbergen, R.F.P., Broxterman, Q.B, Hulshof, L.A., Pouwer, K.L. \& Vries, T.R. (2000) Dutch resolution of racemic 4-hydroxy- and 4fluorophenylglycine with mixtures of phenylglycine and (+)-10-camphorsulfonic acid, Tetrahedron: Asymmetry, Vol. 11, No. 6, (April 2000), pp. 1343-1351, ISSN 09574166

Kleinman, D. A. (1962). Theory of second harmonic generation of light. Physical Review, Vol. 128, No. 4, (1962) pp. 1761-1775.

Kostyanovsky, R. G., Kostyanovsky, V. R., \& Kadorkina, G. K. (2009) The enigma of a ( \pm )tartaric acid-urea cocrystal, Mendeleev Communications, Vol. 19, No.1, (2009), pp. 17- 18, ISSN 0959-9436 
Kuroda, R. \& Honma, T. (2000) Cd spectra of solid-state samples, Chirality, Vol. 12, No. 4, (April 2000), pp. 269-277, ISSN 0899-0042

Kurtz, S. \& Perry, T. (1968) A powder technique for the evaluation of nonlinear optical materials, Journal of Applied physics, Vol.39, No. 8, (July 1968), pp.3798-3813, ISSN 0021-8979.

Lorenz, H., Perlberg, A., Sapoundjiev, D., Elsner, M. P., \& Seidel-Morgenstern, A. (2006), Crystallization of enantiomers, Chemical Engineering and Processing: Process Intensification, Vol. 45, No. 10, (April 2006), pp. 863 - 873, ISSN 0255-2701

Marchand, P., Lefebvre, L., Querniard, F., Cardinael, P., Perez, G., Counioux, J-J \& Coquerel, G. (2004), Diastereomeric resolution rationalized by phase diagrams under the actual conditions of the experimental process, Tetrahedron: Asymmetry, Vol.15, No.16, (August 2004), pp. 2455-2465, ISSN 0957-4166

Marckwald, W., (1896) Ueber ein bequemes Verfahren zur Gewinnung der Linksweinsäure, Berichte der deutschen chemischen Gesellschaft, Vol.29, No.1, (April 1896), pp.4243

Ndzié, E., Cardinael, P., Schoofs, A. R., \& Coquerel, G. (1997), An efficient access to the enantiomers of [alpha]-methyl-4-carboxyphenylglycine via a hydantoin route using a practical variant of preferential crystallization as3pc (auto seeded programmed polythermic preferential crystallization), Tetrahedron: Asymmetry, Vol. 8, No. 17, (September 1997), pp. 2913-2920, ISSN 0957-4166

Kocher-Becker, U. , Kocher, W. \& Ockenfels, H. (1982), Teratogenic activity of a hydrolytic thalidomide metabolite in mice, Naturwissenschaften, Vol. 69, No. 4, (Avril 1982), pp. 191-192, ISSN 0028-1042

Pasteur, L. (1853), Transformation des acides tartriques en acide racémique - Découverte de l'acide tartrique inactif. Nouvelle méthode de séparation de l'acide racémique en acides tartriques droit et gauche. Compte-rendus de l'Académie des Sciences, Vol. 37, (Juillet 1853), pp.162-166

Pope, W.J. \& Peachey, S.J. (1899), The application of powerful optically active acids to the resolution of externally compensated basic substances. Resolution of tetrahydroquinaldine, Journal of Chemical Society Transactions, Vol. 75, (January 1899), pp. 1066-1093, ISNN 0368-1645

Renou, L., Morelli, T., Coste, S., Petit, M.-N., Berton, B., Malandain, J.-J. \& Coquerel, G., (2007), Chiral discrimination at the solid state of the methyl 2(diphenylmethylsulfinil)acetate, Crystal Growth \& Design, Vol. 7, No. 9, (August 2007), pp.1599-1607, ISSN 1528-7483

Stinson, S.C. (2000). , Chiral Drugs, Chemical and Engeniering news, Vol. 78, No. 43, pp. 55-78 (October 2000), ISSN 0009-2347

Subramanian, G., (2006). Chiral Separation Techniques: A Practical Approach $\left(3^{\text {rd }}-18^{\text {th }}\right.$ October), Wiley-VCH Verlag GmbH, ISBN: 978-3-527-31509-3, Weinheim, Germany.

Vries, T., Wynberg, H.,Van Echten, E.A, Koek, J.A, Ten Hoeve, W.A., Kellogg, R.M., Broxterman, Q.B., Minnaard, A.B, Kaptein, B.B, Van Der Sluis, S., Hulshof, L. \& Kooistra, J. (1998), The family approach to the resolution of racemates, Angewandte Chemie - International Edition, Vol. 37, No 17, (September 1998), pp. 2349-2354, ISSN 1433-7851

Wermester, N., Aubin, E., Pauchet, M., Coste, S., \& Coquerel, G. (2007). Preferential crystallization in an unusual case of conglomerate with partial solid solutions. Tetrahedron: Asymmetry, Vol. 18, No. 7, (2007), pp. 821-831, ISSN 0957-4166 


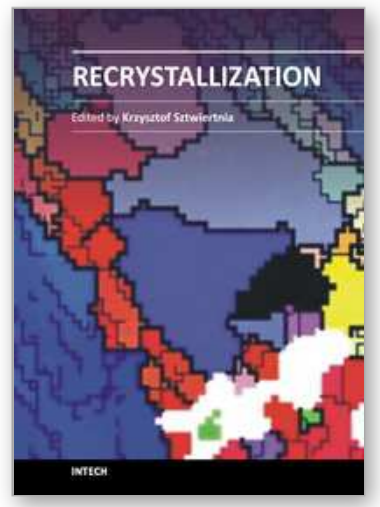

\author{
Recrystallization \\ Edited by Prof. Krzysztof Sztwiertnia
}

ISBN 978-953-51-0122-2

Hard cover, 464 pages

Publisher InTech

Published online 07, March, 2012

Published in print edition March, 2012

Recrystallization shows selected results obtained during the last few years by scientists who work on recrystallization-related issues. These scientists offer their knowledge from the perspective of a range of scientific disciplines, such as geology and metallurgy. The authors emphasize that the progress in this particular field of science is possible today thanks to the coordinated action of many research groups that work in materials science, chemistry, physics, geology, and other sciences. Thus, it is possible to perform a comprehensive analysis of the scientific problem. The analysis starts from the selection of appropriate techniques and methods of characterization. It is then combined with the development of new tools in diagnostics, and it ends with modeling of phenomena.

\title{
How to reference
}

In order to correctly reference this scholarly work, feel free to copy and paste the following:

Valérie Dupray (2012). Recrystallization of Enantiomers from Conglomerates, Recrystallization, Prof. Krzysztof Sztwiertnia (Ed.), ISBN: 978-953-51-0122-2, InTech, Available from:

http://www.intechopen.com/books/recrystallization/recrystallization-of-pure-enantiomers-from-conglomerates

\section{INTECH}

open science | open minds

\section{InTech Europe}

University Campus STeP Ri Slavka Krautzeka 83/A 51000 Rijeka, Croatia

Phone: +385 (51) 770447

Fax: +385 (51) 686166 www.intechopen.com

\section{InTech China}

Unit 405, Office Block, Hotel Equatorial Shanghai No.65, Yan An Road (West), Shanghai, 200040, China 中国上海市延安西路65号上海国际贵都大饭店办公楼405单元 Phone: +86-21-62489820

Fax: +86-21-62489821 
(C) 2012 The Author(s). Licensee IntechOpen. This is an open access article distributed under the terms of the Creative Commons Attribution 3.0 License, which permits unrestricted use, distribution, and reproduction in any medium, provided the original work is properly cited. 